Supporting Information for

\title{
Catalase and Epoxidation Activity of Manganese Salen Complexes Bearing Two Xanthene Scaffolds
}

\author{
Jenny Y. Yang and Daniel G. Nocera* \\ Department of Chemistry, 6-335, Massachusetts Institute of Technology, 77 \\ Massachusetts Avenue, Cambridge, Massachusetts 02139-4301
}

Index

Page

Figure S1. ${ }^{1} \mathrm{H}$ NMR and MS characterization of - (ONN) — ligand impurity

produced in the synthesis of $\mathbf{1 3}$

Figure S2. $\mathrm{O}_{2}$ evolution (and mass spec) by $\mathbf{1 8}$ after addition of $\mathrm{H}_{2} \mathrm{O}_{2}$

Figure $\mathrm{S} 3 . \mathrm{O}_{2}$ evolution by $\mathbf{1 5}$ in under phase transfer and homogeneous solution conditions 


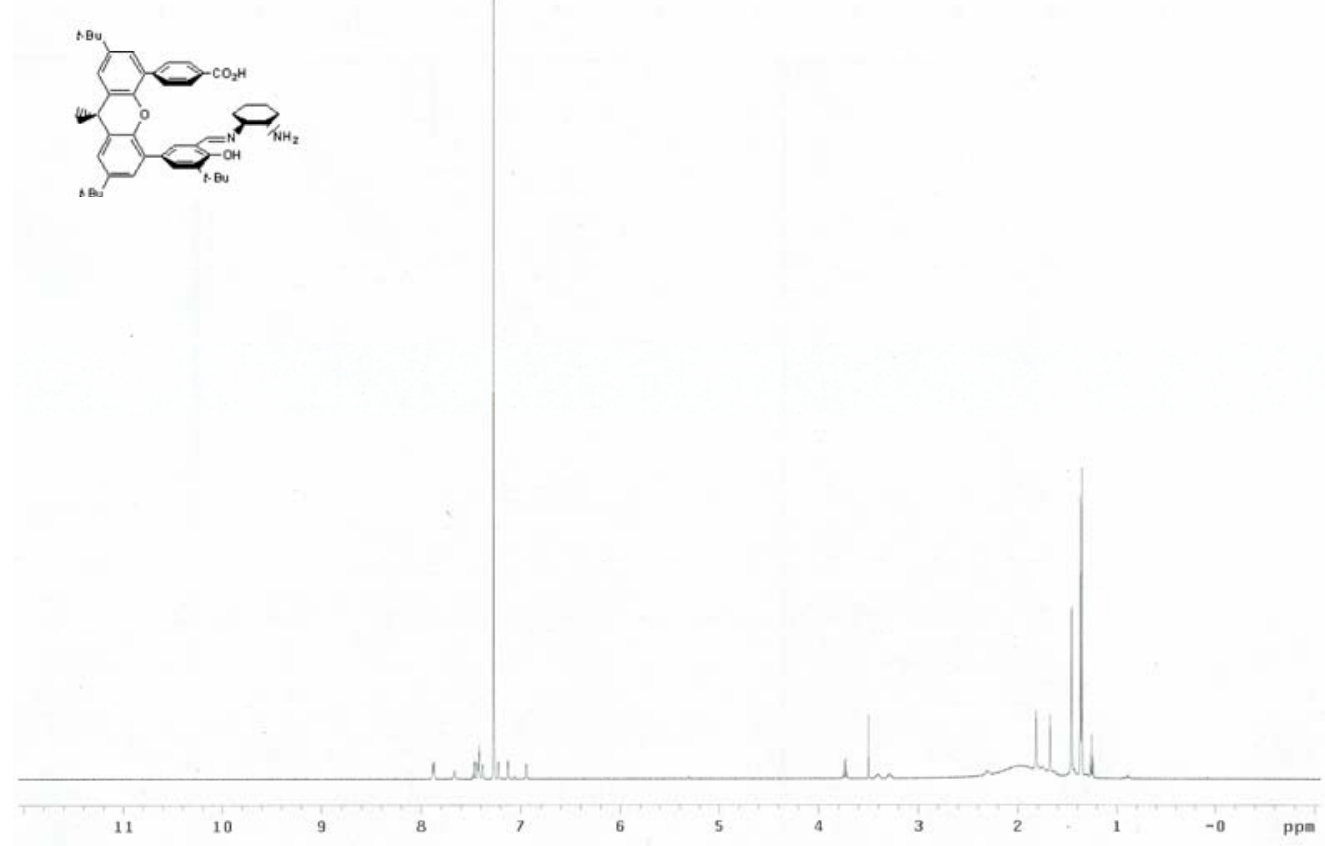

Figure S1.1. ${ }^{1} \mathrm{H}$ NMR Spectra for $-(\mathrm{ONN})$ - ligand impurity resulting from the condensation reaction of 13 with an excess of $(1 R, 2 R)-(-)$-1,2-diaminocyclohexane.

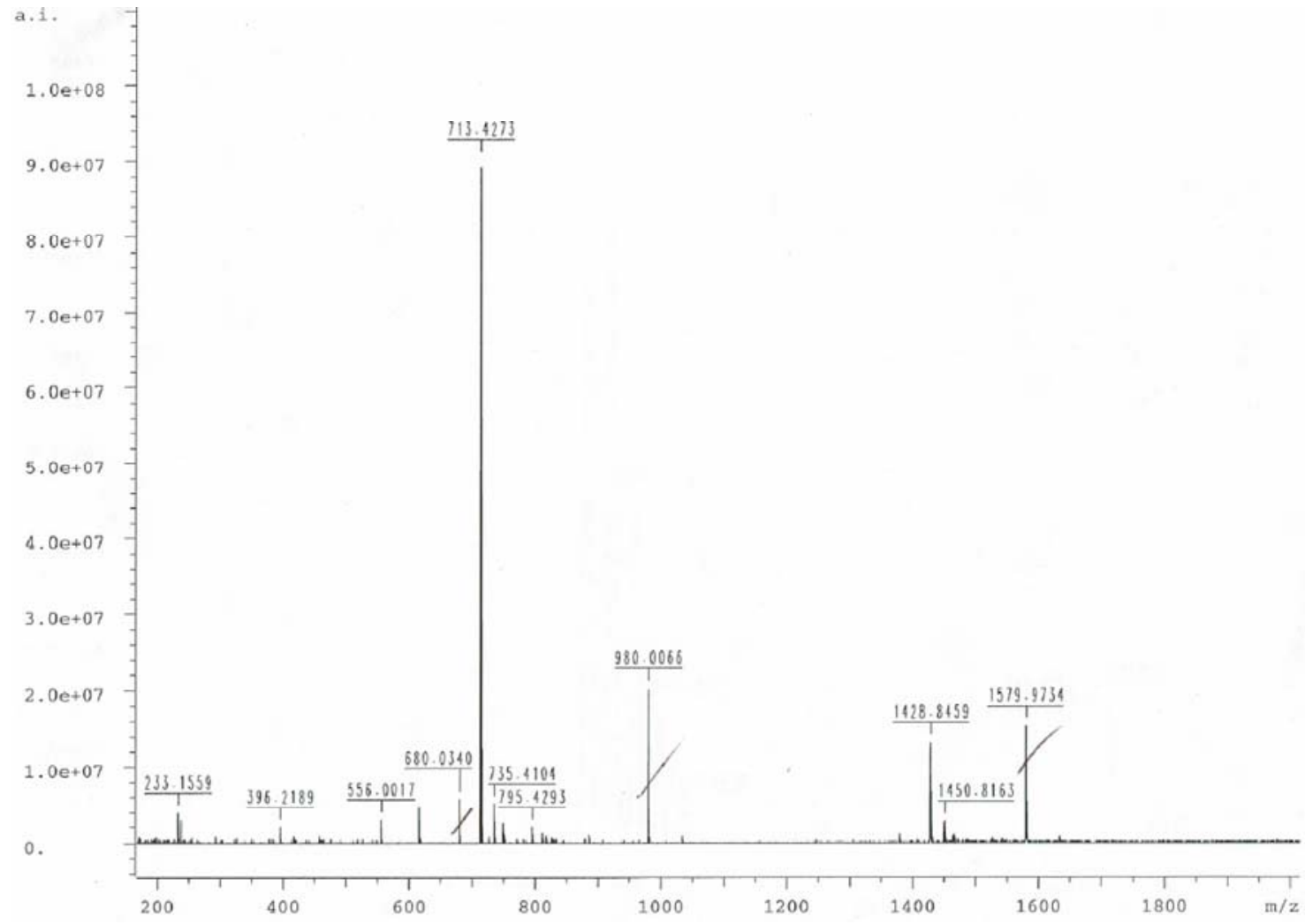

Figure S1.2. Mass Spectra for - $(\mathrm{ONN})$ - ligand resulting from the condensation reaction of $\mathbf{1 3}$ with an excess of $(1 R, 2 R)-(-)-1,2$-diaminocyclohexane. The peaks with a slash through them correspond to the added internal standard. 


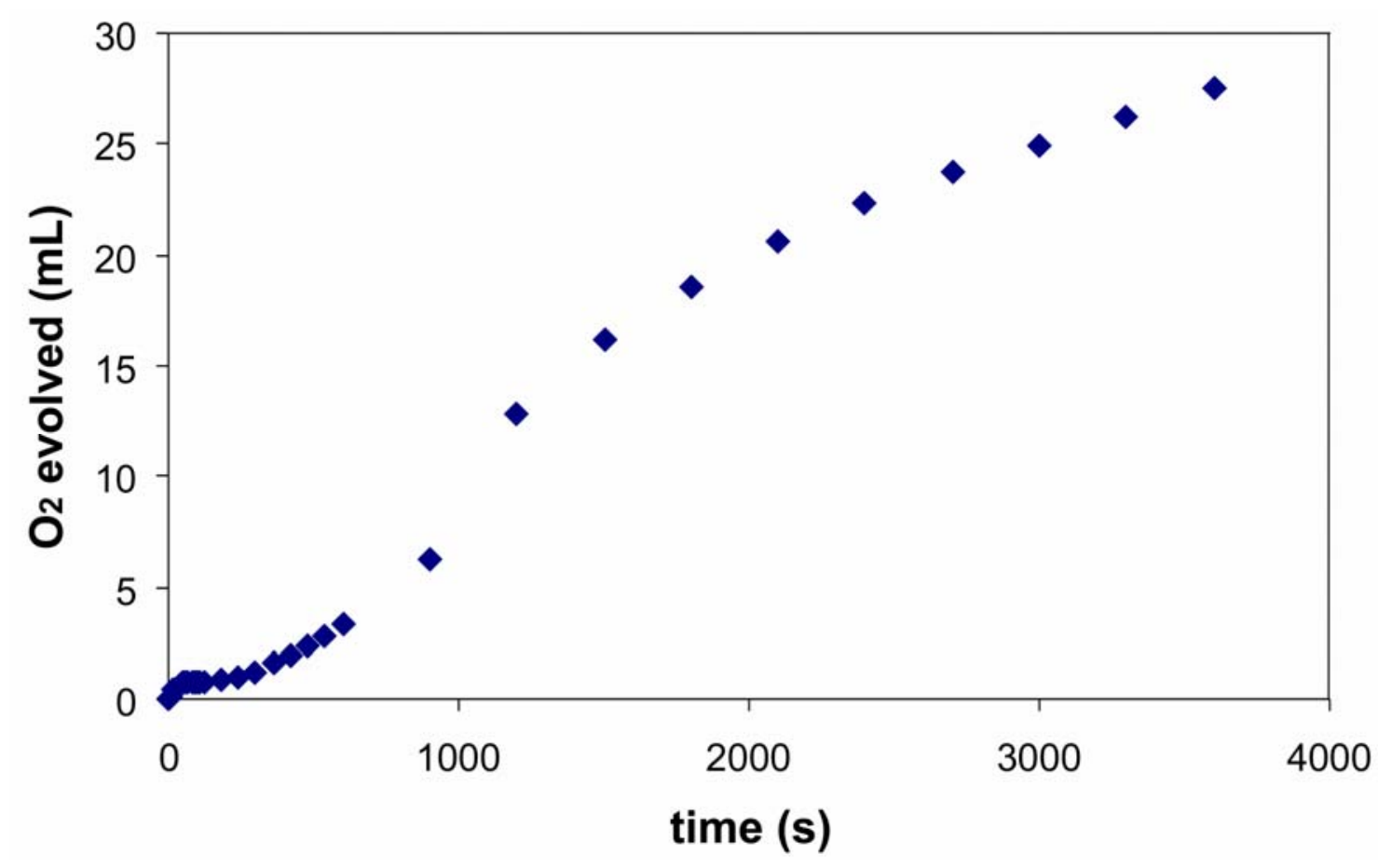

Figure S2.1. Oxygen release from hydrogen peroxide dismutation catalyzed by manganese compound 18 over one hour.

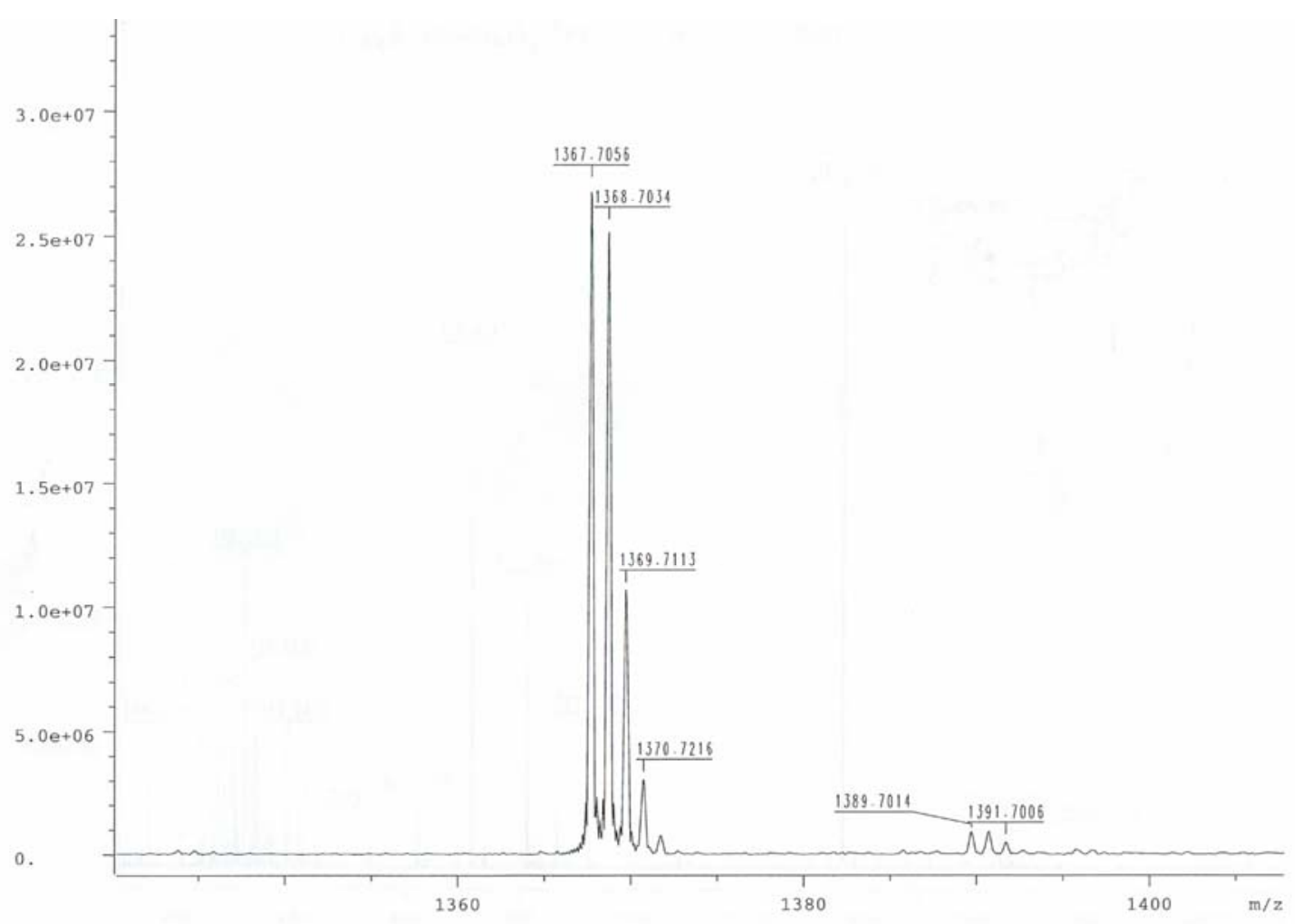

Figure S2.2. Mass spectra evidence of the doubly deprotected species from the crude product isolated 20 minutes after addition of $\mathrm{H}_{2} \mathrm{O}_{2}$ to manganese catalyst $\mathbf{1 8}$. 


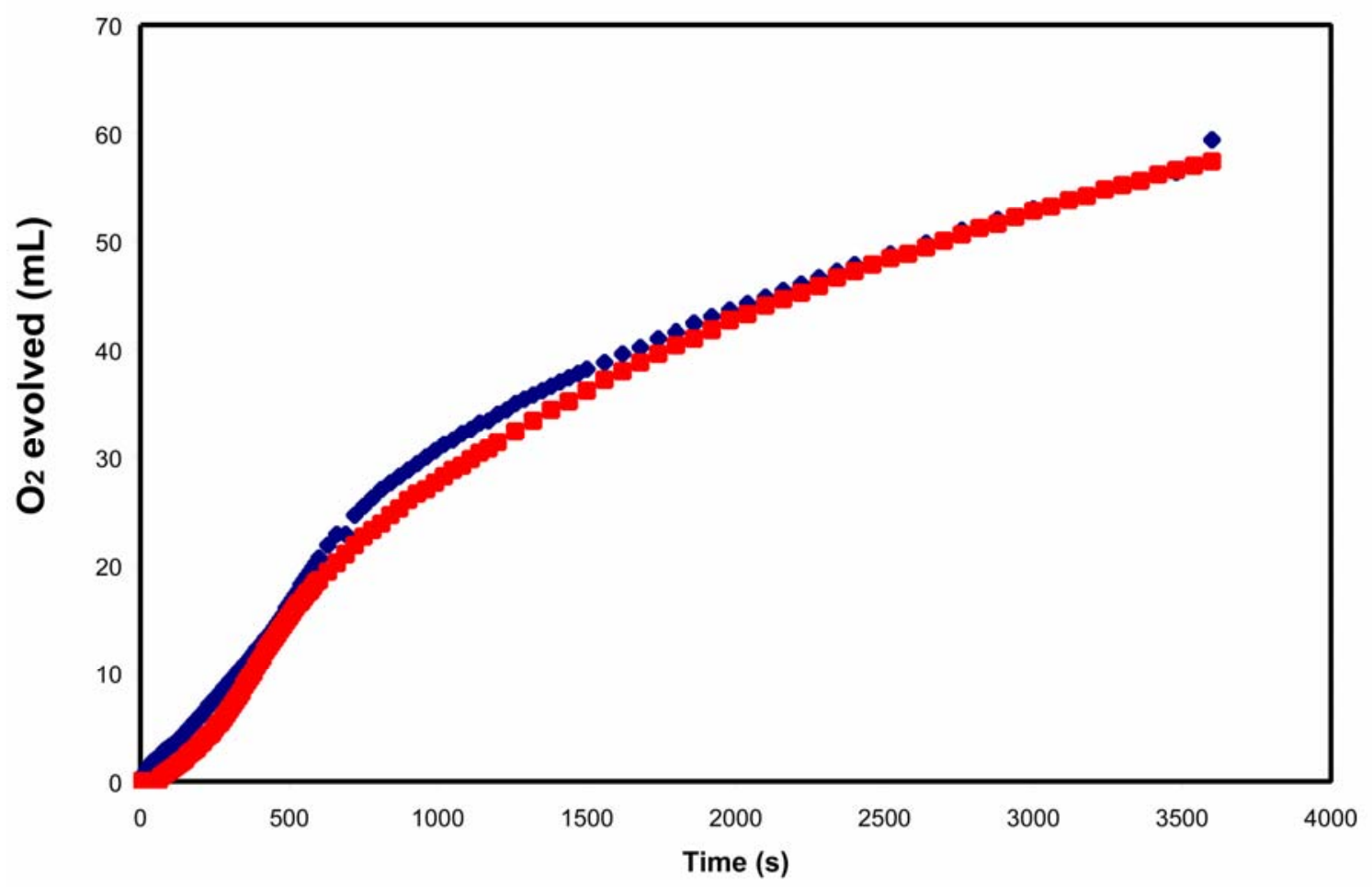

Figure S3. Oxygen release from hydrogen peroxide dismutation catalyzed by manganese compound $\mathbf{1 5}$ in (i) 2:1 dichloromethane:methanol ( $\downarrow$ ) and (ii) 2:1 tetrahydrofuran: methanol ( $\square)$ over one hour under the same substrate and catalyst conditions. 